\title{
A COMPARISON BETWEEN METHODS FOR ASSESSMENT OF WHOLE-BODY VIBRATION EXPOSURE: A CASE STUDY IN A LIMESTONE QUARRY
}

\author{
G. ALFARO DEGAN, G. COLTRINARI, D. LIPPIELLO \& M. PINZARI \\ Department of Engineering, University of Roma Tre, Rome, Italy.
}

\begin{abstract}
The problem of the whole body vibration (WBV) exposure for operators in the workplace has been analyzed by many researchers that have studied for a long time the complex relationships between this phenomenon and human health risks. Previous studies have shown that drivers of different vehicles, in particular operators in mining activities, are afflicted by serious musculoskeletal injuries due to WBV exposure. Criteria in order to measure and assess equivalent daily exposure, associated with different operations of the vehicles, are referred to standards ISO2631-1, based on method of the frequencyweighted equivalent continuous root mean squared (r.m.s.) acceleration. Numerous studies point out the complexity to outline a clear relationship between WBV exposure and the human health disorders. An experimental campaign was realized in a limestone quarry near Rome and vibration measurements were recorded on four different mining vehicles (dumper, jeep, digger and puncher machine). The vibratory signal was taken at the seat operator/seat interface (X, Y and $\mathrm{Z}$ axes) in accordance with the ISO 2631-1 during daily quarry operations. The data obtained were elaborated and finally the results are presented in order to evidence the difference of WBV exposure between the specific operating tasks and some methods for the purpose of exposure dose reduction are suggested.
\end{abstract}

Keywords: earth moving machinery, quarry, whole body vibration, workers exposure

\section{INTRODUCTION}

In the quarry activities, the driver's exposure to whole-body vibration (WBV) on any type of vehicles is a widespread occupational risk factors [1]. It may cause adverse relevant health effects or discomfort on operators driving machinery [2]. Numerous researchers point out that WBV exposure is suspected to be the cause dangerous of health effects [3] such as fatigue, lower back pain [4], vision problems, interference with or irritation to the lungs, abdomen, or bladder, and adverse effects to the digestive, genital/urinary, and female reproductive systems [5]. Several awkward problems have to be faced in epidemiological research on the relationship between human health disorders and the dose exposure [6], even if there is not yet enough epidemiological evidence to outline a clear relationship between WBV exposure and health disorders [7]. The drivers of all types of vehicles frequently report problems from these spinal regions [8], particularly lumbar and low back pains are the most relevant effects [9]. The exposure effects depend on many factors: the magnitude of the waveform [10], the exposure time for the occupant, the driver's position [11] and types of vehicles [12]. Furthermore, the worker's anthropometrics characteristics, the driver's height and weight play a relevant role on the exposure [13]. Information regarding the chronic effects of WBV is still in infancy but, despite of few reliable data that characterize health hazards and their health outcomes, there is abundant information regarding subjective responses to vibration $[14,15]$. In fact, WBV generates systemic effects on entire human body and numerous studies are carried out in order to highlight the human response to a source vibration [16]. A limit of these studies is that the tests are performed in laboratory settings; thus, they only evaluate the sinusoidal vibration and are not representative of the real-work conditions. About the quarry activities, numerous studies have explored WBV 
exposure levels during the operations of large earth moving equipment [17]. The loadhaul-dump (LHD) vehicles are a potential dangerous source of hazards health human due to the rough terrain, heavy loading and haul travels [18]. The long-term exposure to WBV has multiple shocks during the unloaded travels can lead to adverse effects on the lumbar spine. Generally, the operations containing multiple shocks cause injury for several reasons, like the increase of mechanical stress caused by seat postures, the change to the way the human body responds to multiple load caused by various postures, potential changes to the neuromuscular control system [19], which will effect passive and active stabilization and buckling, or softening of the intervertebral disc [11]. The epidemiological studies show that the highest levels of vertical vibration measured in off-road vehicles generate low back disorders and that the risk factors are relevant for acceleration of more than $0.5 \mathrm{~m} / \mathrm{s}^{2}$. The International standard ISO 2631-1 for exposure assessment shows the measure methods and indicates a health caution zone between 0.45 and $0.8 \mathrm{~m} / \mathrm{s}^{2}$ for 8 -h exposure [20]. The extractive sector has particular characteristics due to the complexity of the production process, which requires the employment of specific quarry machinery and vehicles [21]. These vehicles, like dumper, jeep, puncher machine, excavator, LHD vehicles, are a source of high vibration levels, especially when the vehicles are employed in the ordinary quarry activities. Therefore, it is possible to analyze the problem of the WBV exposure in terms of purely monitoring. The aim of this paper is to compare the WBV exposure of the same operator for different vehicles of the quarry activities in order to highlight the influence of the specific activities on the driver's exposure.

\section{METHODS AND MATERIALS}

This work is based on a measurement campaign realized in a limestone quarry $100 \mathrm{~km}$ far away from Rome. The WBV exposure was measured for the same operator on four different vehicles. After the measurements, the daily dose was assessed and finally all sets of data were compared for the purpose of highlighting how the specific quarry activity determines the driver's exposure. The exposure assessment was carried out according to the specifications established by the ISO 2631-1 (97) [20].

\subsection{Vehicles and test site}

The measurements of WBV exposure were realized on a total of four different typical quarry machineries: LHD truck, excavator, jeep and puncher machine (see Fig. 1).

All vehicles were reported to be in 'good' and 'very good' condition by the vehicle operator with maintenance occurring at regular intervals (every 250 operational hours). The characteristics of each vehicle can be seen in the following Table 1, along with their respective operative task and the soil conditions under which there were tested.
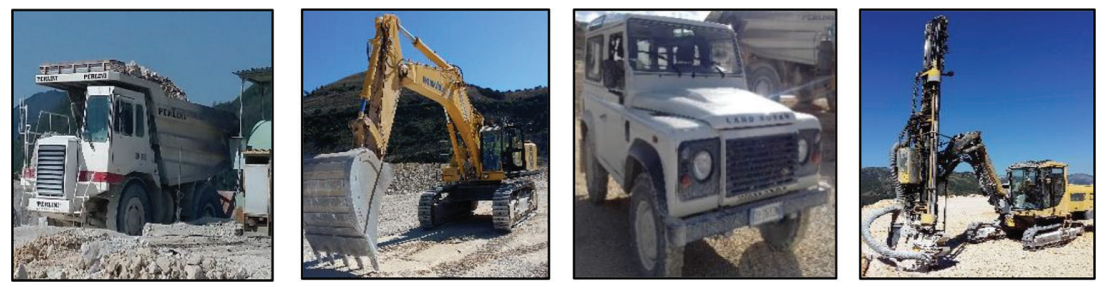

Figure 1: From left to right, LHD truck, excavator, jeep and puncher machine. 
Table 1: Vehicles characteristics.

\begin{tabular}{llll}
\hline Vehicles & Year & Task & Ground condition \\
\hline LHD truck & 2004 & Transfer heart & Medium (compact rock ground) \\
excavator & 2015 & Move earth / dig holes & Hard (fractured rock ground) \\
jeep & 2016 & Transfer workers & Medium (compact rock ground) \\
puncher machine & 2006 & perforate holes & Hard (fractured rock ground) \\
\hline
\end{tabular}

The tests were realized in a limestone quarry on the top of a mountain during the winter months in the centre of Italy. According to the ISO 2631-1 WBV standards [20] measurement durations should be of sufficient length to ensure statistical precision and the representativeness of the sample. Attention was taken to ensure that the equipment was operated at the normal task operating speeds. The length of the time was chosen to ensure that all aspects (events) of the work cycle were represented. Therefore, the testing period was chosen based on the length of time required to complete at least one complete work cycle for each vehicle. Weather was always in dry conditions and typical temperatures were approximately $10 \pm 5^{\circ} \mathrm{C}$.

\subsection{Equipment operator}

The participant operator was a volunteer and he allowed onsite access to each vehicle for measurement. The experimental driver sample was chosen for the reason that he was an expert driver of quarry vehicles and had more than 20 years of experience in these types of tasks. Prior to measurements, the operator completed a questionnaire to gather information on anthropometric characteristics, work experience, and any existing musculoskeletal disorders. The answers showed that he was $1.80 \mathrm{~m}$ tall, his weight was $80 \mathrm{~kg}$ and did not have any low back gain injuries. Furthermore, the mean time of each specific activity was required in order to compute the operator's exposure. The tasks, which the driver was required to perform, were his usual everyday work in the same boundary conditions.

\subsection{Device and data acquisition}

In order to measure the driver's exposure, a SEN-027 PCB Piezotronics seat-pad triaxial accelerometer was positioned on the operator's seat, in accordance with the ISO 2631-1 guidelines [20], on the surface between driver and seat by a scotch tape. The following Table 2 reports instrument characteristics.

This accelerometer was specially designed for vibration analysis and the WBV monitoring on vehicles. The device was calibrated prior to the data collection in accordance with the manufacturer's guidelines (the signal had a $9.8 \mathrm{~m} / \mathrm{s}^{2} \mathrm{r} . \mathrm{m} . \mathrm{s}$ value and a $159.2 \mathrm{~Hz}$ frequency).

Table 2: Characteristics of instruments.

\begin{tabular}{lll}
\hline Model & Sensivity & Position \\
\hline Traxial accelerometer & X axis:10.52 $\mathrm{mV} /\left(\mathrm{m} / \mathrm{s}^{2}\right)$ & $\begin{array}{l}\text { Driving seat of the truck in the position } \\
\text { SEN027-PCB }\end{array}$ \\
& Yaxis:10.55 $\mathrm{mV} /\left(\mathrm{m} / \mathrm{s}^{2}\right)$ & $\begin{array}{l}\text { which corresponds to the driver's sacroiliac } \\
\text { Z axis: } 10.58 \mathrm{mV} /\left(\mathrm{m} / \mathrm{s}^{2}\right)\end{array}$ \\
& $\begin{array}{l}\text { joints } \\
\text { (his buttocks) }\end{array}$ \\
\hline
\end{tabular}


The tri-axial accelerometer was connected to the Sound-book device, which recorded the incoming vibration signal through Samurai software during daily quarry operations. The sampling frequency was $1250 \mathrm{~Hz}$ according to Shannon theorem and while the frequency range was from $0.5 \mathrm{~Hz}$ to $250 \mathrm{~Hz}$. The acceleration levels were obtained in the $\mathrm{x}, \mathrm{y}$, and $\mathrm{z}$-directions, where the $\mathrm{x}$-axis was positioned for measuring the vibration in the radial direction, the $y$-axis in the orthogonal direction, and the z-axis in the vertical plane. The gain was set with a 1 Volt value in order to avoid overload. The post processing of data was realized through Noise Vibration Work software.

\subsection{Data analysis}

All measurements were made in accordance with the ISO 2631-1 standard for the evaluation of human exposure to the whole-body vibration [20]. The frequency-weighted root mean square acceleration (r.m.s.) was calculated using the following expression (1):

where:

$$
A(8)=a_{w} \sqrt{\frac{T_{e s p}}{8}} \mathrm{~m} / \mathrm{s}^{2}
$$

$\mathrm{A}(8)$ is the daily dose expressed as $\left[\mathrm{m} / \mathrm{s}^{2}\right]$

$\mathrm{T}_{\text {exp }}$ is the exposure time expressed as [hr]

$\mathrm{a}_{\mathrm{w}}$ is the equivalent continuous RMS acceleration also expressed as $\left[\mathrm{m} / \mathrm{s}^{2}\right]$

Italian Decree-Law 81/2008 establishes that the evaluation of the risk to whole-body vibration exposure is based on evaluation of the daily exposure $\mathrm{A}(8)$ expressed as the equivalent continuous r.m.s. acceleration over an height hour period. It is calculated as the highest (r.m.s.) value of the frequency-weighted accelerations, determined on the three orthogonal axes following the expression (2):

$$
\mathrm{a}_{\mathrm{w}}=\max \left(\mathrm{K}_{\mathrm{x}} \mathrm{a}_{\mathrm{wx}}, \mathrm{K}_{\mathrm{y}} \mathrm{a}_{\mathrm{wy}}, \mathrm{K}_{\mathrm{z}} \mathrm{a}_{\mathrm{wz}}\right)
$$

where $\mathrm{a}_{\mathrm{w}, \max }$ is the maximum value among $1.4 \cdot \mathrm{a}_{\mathrm{w}, \mathrm{x}}, 1.4 \mathrm{a}_{\mathrm{w}, \mathrm{y}}$ and $1 \cdot \mathrm{a}_{\mathrm{w}, \mathrm{z}}$ for a seated or standing worker [20].

\section{RESULTS}

The following graphs show the time history (trend of signal during along the time) and the frequency spectrum (the acceleration for octave third band frequency) for a puncher machine. The blue line represents the signal along $\mathrm{X}$ axis, the red line along $\mathrm{Y}$ axis and the green line along $\mathrm{Z}$ axis.

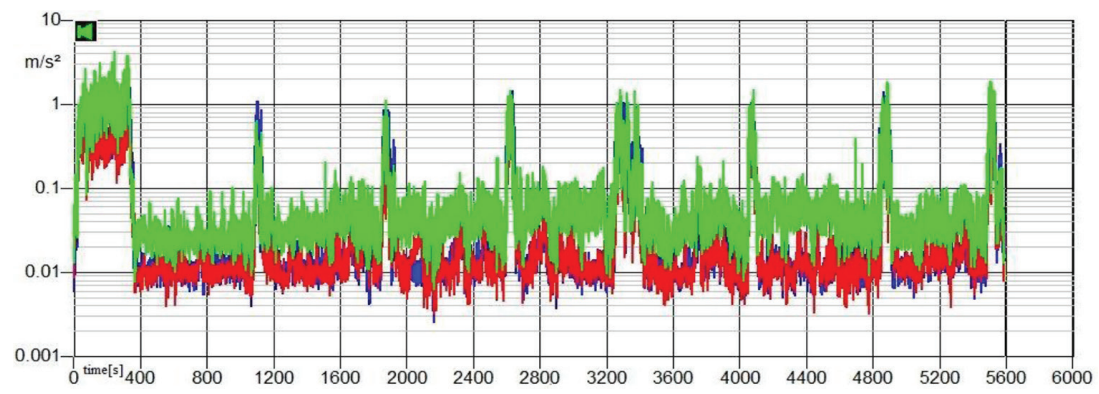

Figure 2: Signal along three axes of puncher machine. 


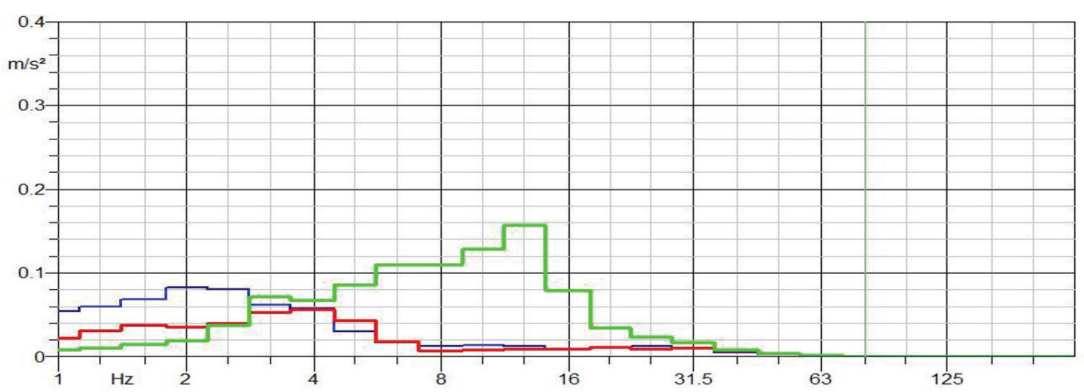

Figure 3: Frequency spectrum of puncher machine.

Furthermore, the signal of excavator time history and the corresponding frequency spectrum are reported in the following graphs.

Frequency-weighted r.m.s accelerations, instantaneous peak accelerations and dominant frequencies measured at the operator/seat interface under typical working conditions are summarized in Table 3. Each task time was estimated on the base of the operator's interview. Firstly, the task time during a work week (5 days) and later the mean day time are computed. The Estimated Daily Exposure is defined on the basis of the work that the operator carries out along the whole day. In order to predict health risk associated with the operation of each specific task, the 8 -h equivalent frequency weighted r.m.s acceleration value $(\mathrm{A}(8))$ is computed.

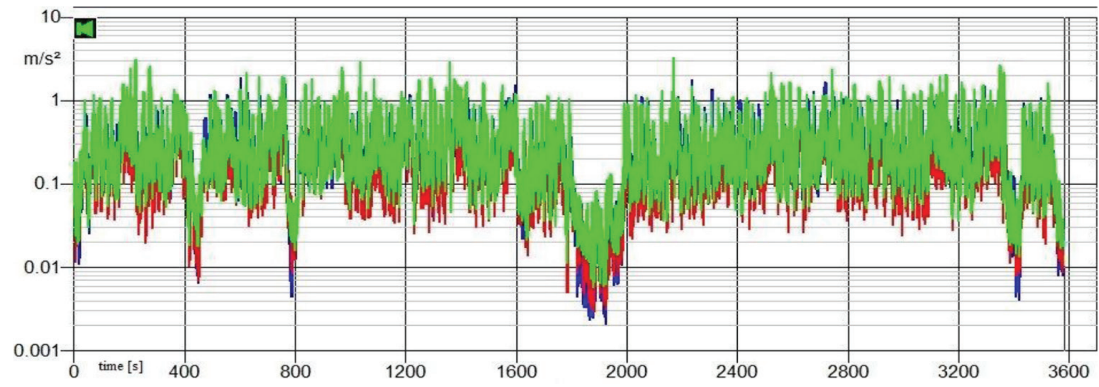

Figure 4: Time history of excavator.

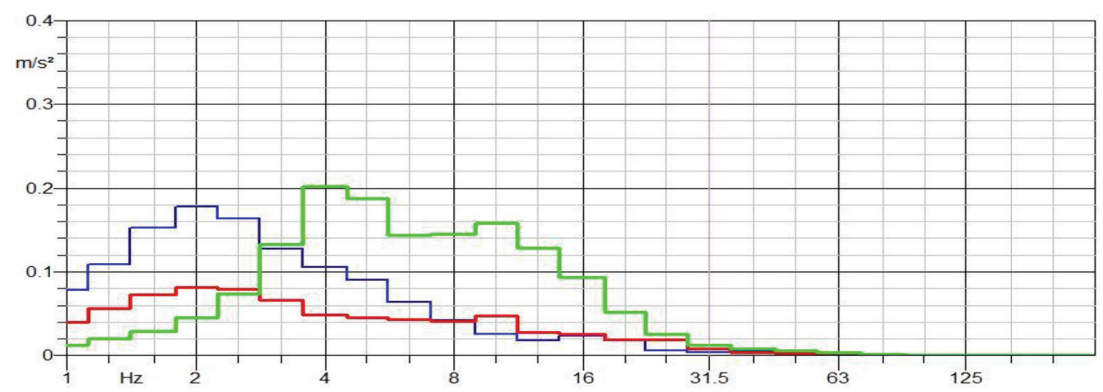

Figure 5: Frequency spectrum of excavator. 
Table 3: Data recorded for all vehicles.

\begin{tabular}{|c|c|c|c|c|}
\hline Parameters & Jeep & LHD vehicle & Puncher machine & Excavator \\
\hline Task & $\begin{array}{l}\text { Transport of } \\
\text { workers }\end{array}$ & $\begin{array}{l}\text { Load/Haule/Dump } \\
\text { of the ground }\end{array}$ & Digging holes & $\begin{array}{l}\text { Moving } \\
\text { ground }\end{array}$ \\
\hline Frequency-Weighted & $\mathrm{a}_{\mathrm{wx}}=0.112$ & $\mathrm{a}_{\mathrm{wx}}=0.229$ & $\mathrm{a}_{\mathrm{wx}}=0.184$ & $\mathrm{a}_{\mathrm{wx}}=0.351$ \\
\hline R.M.S. accelerations & $a_{w y}=0.186$ & $\mathrm{a}_{\mathrm{wy}}=0.261$ & $\mathrm{a}_{\mathrm{wy}}=0.121$ & $a_{w y}=0.199$ \\
\hline$\left(\mathrm{m} / \mathrm{s}^{2}\right)$ & $a_{w z}=0.414$ & $\mathrm{a}_{\mathrm{wz}}=0.451$ & $\mathrm{a}_{\mathrm{wz}}=0.305$ & $\mathrm{a}_{\mathrm{wz}}=0.445$ \\
\hline Instantaneous peak & $\mathrm{a}_{\mathrm{wx}}=1.186$ & $a_{w x}=1.276$ & $a_{w x}=1.642$ & $\mathrm{a}_{\mathrm{wx}}=1.931$ \\
\hline \multirow[t]{2}{*}{ accelerations $\left(\mathrm{m} / \mathrm{s}^{2}\right)$} & $\mathrm{a}_{\mathrm{wy}}=1.298$ & $\mathrm{a}_{\mathrm{wy}}=1.360$ & $a_{w y}=1.409$ & $\mathrm{a}_{\mathrm{wy}}=0.994$ \\
\hline & $\mathrm{a}_{\mathrm{wz}}=2.216$ & $a_{w z}=2.783$ & $\mathrm{a}_{\mathrm{wz}}=4.925$ & $a_{w z}=3.25$ \\
\hline Dominant & $\mathrm{DF}_{\mathrm{x}}=2$ & $\mathrm{DF}_{\mathrm{x}}=1.6$ & $\mathrm{DF}_{\mathrm{x}}=2$ & $\mathrm{DF}_{\mathrm{x}}=2$ \\
\hline Frequencies (Hz) & $\mathrm{DF}_{\mathrm{y}}=1.6$ & $\mathrm{DF}_{\mathrm{y}}=1.3$ & $\mathrm{DF}_{\mathrm{y}}=4$ & $\mathrm{DF}_{\mathrm{y}}=2$ \\
\hline & $\mathrm{DF}_{\mathrm{z}}=2.5$ & $\mathrm{DF}_{\mathrm{z}}=2$ & $\mathrm{DF}_{z}=12.5$ & $\mathrm{DF}_{\mathrm{z}}=4$ \\
\hline $\begin{array}{l}\text { Estimated Time of } \\
\text { each task (min.) }\end{array}$ & 10 & 122 & 336 & 12 \\
\hline $\begin{array}{l}\text { Driver's daily exposure } \\
\text { for specific task } A(8)\end{array}$ & 0.05 & 0.22 & 0.26 & 0.07 \\
\hline $\begin{array}{l}\text { Estimated Daily Expo- } \\
\text { sure }(8 \mathrm{~h})\end{array}$ & 0.41 & 0.45 & 0.3 & 0.49 \\
\hline
\end{tabular}

\section{DISCUSSION}

The WBV exposure was evaluated on four quarry vehicles for different tasks of the operator on the vehicles. The measures were realized according to ISO2631-1 based on the worst axis method. Measured frequency-weighted r.m.s. accelerations reported in this study were similar to the values previously reported for many quarry vehicles. The dominant frequencies are in the 1.3-4 Hz range across all vehicles for both translational ( $\mathrm{x}$ and y axis) while in the $2-12.5 \mathrm{~Hz}$ range in the vertical direction, with the relevant power spectrum falling below $4 \mathrm{~Hz}$. The instantaneous peak acceleration ranges from a low of $0.994 \mathrm{~m} / \mathrm{s}^{2}\left(\mathrm{a}_{\mathrm{wy}}\right.$ excavator) to a high of $4.925 \mathrm{~m} / \mathrm{s}^{2}\left(\mathrm{a}_{\mathrm{wz}}\right.$ puncher machine). The data in Table 2 point out that in terms of exposure for a specific task, the puncher machine is the higher vibration source while the jeep shows minimum $a_{w}$ values. Instead, under the hypothesis that the operator carries out the specific task during all work time $(8 \mathrm{~h})$, the obtained higher daily exposure value results on the excavator while the puncher machine proves to be the least dangerous vehicle.

\section{CONCLUSIONS}

The repeated measurements of the vibrations on different quarry vehicles have shown a large range of WBV exposure. If, obtained for each single vehicle, they cannot be taken as indicative of vibration in all vehicles of that category. Despite this limitation, the collected data from the measurements point out that, for most measurements, the vertical axis gives the greatest frequency-weighted acceleration magnitude and thus the r.m.s. acceleration is mostly dominated by vertical vibration. Furthermore, this paper shows that the exposure dose values on the vehicle depend on exposure time and vibration intensity. Consequently, exposure reduction may be achieved by reducing the time for a specific task and through an appropriate 
selection of vehicle model. For example, when the employer coordinates intervention programs, he can choose investing on vehicles innovation and may easily define extra pauses and individual work schedules in which a driver drives for fewer hours per day.

\section{REFERENCES}

[1] Paddan, G.S. \& Griffin, M.J., Evaluation of whole-body vibration in vehicles. Journal of Sound and Vibration, 253(1), pp. 195-213, 2002.

https://doi.org/10.1006/jsvi.2001.4256

[2] Kittusamy, N.K. \& Buchholz, B., Whole-body vibration and postural stress among operators of construction equipment: a literature review. Journal of Safety Research, 35(3), pp. 255-261, 2004.

https://doi.org/10.1016/j.jsr.2004.03.014

[3] Magnusson, M.L. \& Pope, M.H., A review of the biomechanics and epidemiology of working postures (it isn't always vibration which is to blame!). Journal of Sound and Vibration, 215(4), pp. 965-976, 1998.

https://doi.org/10.1006/jsvi.1998.1677

[4] Bovenzi, M., Low back pain disorders and exposure to whole-body vibration in the workplace. Seminars in Perinatology, 20(1), pp. 38-53, 1996.

https://doi.org/10.1016/s0146-0005(96)80056-5

[5] Miyashita, K., Morioka, I., Tanabe, T., Iwata, H. \& Takeda, S., Symptoms of construction workers exposed to whole body vibration and local vibration. International Archives of Occupational and Environmental Health, 64(5), pp. 347-351, 1992. https://doi.org/10.1007/bf00379545

[6] Tiemessen, I.J., Hulshof, C.T.J., \&. Frings-Dresen, M.H.W, An overview of strategies to reduce whole-body vibration exposure on drivers: a systematic review. International Journal of Industrial Ergonomics, 37(3), pp. 245-256, 2007. https://doi.org/10.1016/j.ergon.2006.10.021

[7] Thalheimer, E., Practical approach to measurement and evaluation of exposure to whole-body vibration in the workplace. Seminars in Perinatology, 20(1), pp. 77-89, 1996. https://doi.org/10.1016/s0146-0005(96)80060-7

[8] Hinz, B., Seidel, H., Hofmann, J. \& Menzel, G., The significance of using anthropometric parameters and postures of European drivers as a database for finite-element models when calculating spinal forces during whole-body vibration exposure. International Journal of Industrial Ergonomics, 38(9-10), pp. 816-843, 2008.

https://doi.org/10.1016/j.ergon.2007.10.022

[9] Boshuizen, H.C., Hulshof, C.T.J., \& Bongers, P.M., Long-term sick leave and disability pensioning due to back disorders of tractor drivers exposed to whole-body vibration. International Archives of Occupational and Environmental Health, 62(2), pp. 117-122, 1990. https://doi.org/10.1007/bf00383587

[10] Zimmermann, C.L. \& Cook, T.M., Effects of vibration frequency and postural changes on human responses to seated whole-body vibration exposure. International Archives of Occupational and Environmental Health, 69(3), pp. 165-179, 1997.

https://doi.org/10.1007/s004200050133

[11] Grandjean, E. \& Hünting, W., Ergonomics of posture: review of various problems of standing and sitting posture. Applied Ergonomics, 8(3), pp. 135-140, 1977. https://doi.org/10.1016/0003-6870(77)90002-3 
[12] Alem, N., Application of the new ISO 2631-5 to health hazard assessment of repeated shocks in U.S. army vehicles. Industrial Health, 43(3), pp. 403-412, 2005. https://doi.org/10.2486/indhealth.43.403

[13] Alfaro Degan, G., Lippiello, D. \& Pinzari, M., Whole body vibrations: experimental assessment of anthropometric differences on the effects of WBV exposure in quarry workers. WIT Transactions on The Built Environment, 151, pp. 61-72, 2015.

[14] Schwarze, S., Notbohm, G., Dupuis, H. \& Hartung, E., Dose-response relationships between whole-body vibration and lumbar disk disease: a field study on 388 drivers of different vehicles. Journal of Sound and Vibration, 215(4), pp. 613-628, 1998. https://doi.org/10.1006/jsvi.1998.1602

[15] Maeda S. \& Morioka, M., Measurement of whole-body vibration exposure from garbage trucks. Journal of Sound and Vibration, 215(4), pp. 959-964, 1998. https://doi.org/10.1006/jsvi.1998.1676

[16] Alfaro Degan, G, Lippiello, D., Lorenzetti, S. \& Pinzari, M., Vibration assessing models: comparison between methods. WIT Transactions on Biomedicine and Health, 16, pp. 59-69, 2013.

[17] Schneider, S.P., Kittusamy, N.K., \& Buchholz, B., An ergonomic evaluation of excavating operations: a pilot study. Applied Occupational and Environmental Hygiene, 16(7), pp. 723-726, 2001. https://doi.org/10.1080/10473220120652

[18] Village, J., Morrison, J.B. \&. Leong, D.K.N., Whole-body vibration in underground load-haul-dump vehicles. Ergonomics, 32(10), pp. 1167-1183, 1989. https://doi.org/10.1080/00140138908966888

[19] Bovenzi, M. \& Betta, A., Low-back disorders in agricultural tractor drivers exposed to whole-body vibration and postural stress. Journal of Safety Research, 27(3), pp. 196-197, 1996. https://doi.org/10.1016/0022-4375(96)82246-8

[20] International Organization for Standardization, Mechanical vibration and shock-Evaluation of human exposure to whole-body vibration-Part 1: General requirements, The Organization, 1997.

[21] Frimpong, S., Galecki, G. \& Chang, Z., Dump truck operator vibration control in highimpact shovel loading operations. International Journal of Mining, Reclamation and Environment, 25(3), pp. 213-225, 2011. https://doi.org/10.1080/17480930.2011.595090 